\title{
Pulsed high dose dexamethasone treatment in chronic inflammatory demyelinating polyneuropathy: a pilot study
}

\author{
D S M Molenaar, P A van Doorn, $M$ Vermeulen
}

\begin{abstract}
Six cycles of dexamethasone $(40 \mathrm{mg}$ per day for four sequential days) every 28 days induced remissions in 10 patients with idiopathic thrombocytopenic purpura (ITP). Whether the same results could be achieved in 10 patients with chronic inflammatory demyelinating polyneuropathy (CIDP) was investigated by comparing the Rivermead mobility index (RMI) before and after six cycles of treatment. Three patients discontinued treatment: one because of severe nausea and vomiting and two because of neurological deterioration. All seven patients who completed treatment improved on the RMI. One of these patients had a relapse within two months after the last cycle and six patients were in remission six months after the last dexamethasone cycle.

Pulsed high dose dexamethasone induced remissions ranged from at least 15 to 23 months. This treatment needs to be tested against standard treatment in a randomised study.
\end{abstract}

(F Neurol Neurosurg Psychiatry 1997;62:388-390)

Keywords: chronic inflammatory demyelinating polyneuropathy; dexamethasone; Rivermead mobility index

Department of

Neurology, Academic

Medical Center,

University of

Amsterdam,

Amsterdam, The

Netherlands

D S M Molenaar

M Vermeulen

Department of

Neurology, Academic

Hospital Rotterdam,

Rotterdam, The

Netherlands

P A van Doorn

Correspondence to:

Dr D S M Molenaar,

Department of Neurology

(H2-214), Academic

Medical Center,

PO Box 22700,

$1100 \mathrm{DE}$ Amsterdam

The Netherlands.

Received 6 September 1996

and in revised form

9 December 1996

Accepted 13 December 1996
Several treatments may be effective In chronic inflammatory demyelinating polyneuropathy (CIDP) ${ }^{1-6}$ To maintain the best possible functional health status patients may need protracted treatment. ${ }^{7}$

Recently, remissions after treatment with pulsed high dose dexamethasone have been reported in patients with chronic idiopathic thrombocytopenic purpura (ITP) ${ }^{8}$ There are similarities in treatment response between ITP and CIDP. The first treatment of a patient with CIDP with intravenous immunoglobulins (IVIg) was based on the reports of a beneficial effect of similar treatment in ITP. ${ }^{9}$ The effects of IVIg and plasma exchange, however, are CIDP and many patients who are treated with corticosteroids have a relapse when the dosage is reduced. often short lived in patients with ITP and
Six cycles of four sequential days with 40 mg dexamethasone per day every 28 days was studied in 10 patients with a relapse of ITP after standard treatment. All 10 patients had increased platelet counts, which remained stable for at least six months after the last dexamethasone cycle. ${ }^{8}$ Serious side effects did not occur and this treatment was well tolerated by the patients.

We treated 10 patients with CIDP with pulsed high dose dexamethasone. The first question was whether this therapy induces remission in patients with CIDP. The second question was whether these patients had clinically significant improvement.

\section{Material and methods}

Ten consecutive patients with CIDP were included in the study. The diagnosis was established by the neurologist in charge of the patient and fulfilled the clinical and electrophysiological criteria of the Ad Hoc Committee. ${ }^{10}$ All patients were deteriorating at the time of enrollment. Dexamethasone was given in six cycles; $40 \mathrm{mg}$ per day for four sequential days in weeks $1,4,7,11,15$, and 19.

Remission was defined as a treatment free period of six months after the last dexamethasone cycle during which clinical improvement was maintained and deterioration did not occur. Changes in functional health status were measured with the Rivermead mobility index (RMI). In this scale the ability to perform the following activities without help of another person is scored: turning over in bed; getting from lying to sitting; maintaining sitting balance; getting from sitting to standing; standing unsupported; transferring; walking inside with an aid if needed; managing stairs; walking outside on even ground; walking inside with no aid; picking up something from the floor; walking outside over uneven ground; bathing; going up and down four steps with no rail; running $10 \mathrm{~m}$ without limping. The highest score, 15 , is the best status. Maximum disagreement between two observers was never greater than two points. ${ }^{11}$ Clinically significant improvement was defined as improvement of three or more points on the RMI.

Before the first cycle, after the last cycle, and six months after the last cycle or earlier if 


\begin{tabular}{|c|c|c|c|c|c|c|c|}
\hline \multirow[b]{2}{*}{ No } & \multirow{2}{*}{$\begin{array}{l}\text { Sex, } \\
\text { age }(y)\end{array}$} & \multirow{2}{*}{$\begin{array}{l}\text { Duration of } \\
\text { CIDP (months) }\end{array}$} & \multicolumn{3}{|l|}{$R M I$ scoret } & \multirow{2}{*}{$\begin{array}{l}\text { Remission after } \\
\text { dexamethasone } \\
\text { (duration in months) }\end{array}$} & \multirow[b]{2}{*}{ Adverse events } \\
\hline & & & At baseline & After last cycle & Six months later & & \\
\hline $\begin{array}{c}1 \\
2 \\
3^{\star} \\
4 \\
5 \\
6 \\
7^{\star} \\
8 \\
9^{\star} \\
10\end{array}$ & $\begin{array}{l}\text { F, } 60 \\
M, 57 \\
\text { F, 56 } \\
M, 63 \\
M, 47 \\
M, 28 \\
M, 24 \\
M, 71 \\
M, 55 \\
M, 49\end{array}$ & $\begin{array}{r}5 \\
7 \\
19 \\
3 \\
9 \\
5 \\
7 \\
12 \\
3 \\
11\end{array}$ & $\begin{array}{r}2 \\
8 \\
10 \\
3 \\
2 \\
4 \\
2 \\
11 \\
9 \\
8\end{array}$ & $\begin{array}{r}10 \\
15 \\
11 \\
15 \\
15 \\
15 \\
0 \\
13 \\
0 \\
12\end{array}$ & $\begin{array}{r}14 \\
15 \\
12 \\
15 \\
15 \\
15 \\
15 \\
14 \\
1 \\
13\end{array}$ & $\begin{array}{l}\text { No } \\
\text { Yes (22) } \\
\text { No } \\
\text { Yes (23) } \\
\text { Yes (22) } \\
\text { Yes (21) } \\
\text { No } \\
\text { Yes (18) } \\
\text { No } \\
\text { Yes (15) }\end{array}$ & $\begin{array}{l}\text { None } \\
\text { None } \\
\text { Weight gain, malaise, vomiting } \\
\text { None } \\
\text { Slight agitation during 6th cycle } \\
\text { None } \\
\text { Deterioration of weakness } \\
\text { Moderate agitation } \\
\text { Slight agitation, perspiration } \\
\text { Increased blood pressure during } \\
\text { 1st cycle, moderate agitation, } \\
\text { mood changes }\end{array}$ \\
\hline
\end{tabular}

deterioration occurred, the neurologist in charge of the patient carried out an evaluation. Side effects were assessed after each cycle.

We analysed the number of patients who reached remission of at least six months, the changes in functional health scores of each patient, and the side effects of treatment.

\section{Results}

The table shows the characteristics of the 10 patients. Nine patients had a mixed sensorimotor neuropathy and one (7) had a symmetric, pure motor neuropathy. Six patients had a relapsing-remitting course before dexamethasone treatment was started. Five of these $(1,2$, $5,6,7)$ had previously shown a beneficial response to IVIg and one (3) had not responded to IVIg but improved after prednisone and azathioprine. There were four patients $(4,8,9,10)$ newly diagnosed with CIDP. Two patients $(4,9)$ had a chronic progressive course and two $(8,10)$ had a chronic progressive course with fluctuations in neurological signs and symptoms. One of these two patients had an IgA nephropathy which had probably not caused his neuropathy.

Three patients $(3,7,9)$ did not complete dexamethasone treatment. In one patient (3) treatment was stopped because of severe nausea, vomiting, and weight gain during treatment. Dexamethasone was started because she had a relapse while taking $20 \mathrm{mg}$ prednisone daily. After two cycles, dexamethasone was stopped and prednisone was continued. Her neurological signs and symptoms slowly improved. In two patients treatment was stopped because of deterioration of neurological signs and symptoms. One (7) had a pure motor form of CIDP, with a beneficial response to IVIg. He deteriorated dramatically after dexamethasone, and later also after three days of $1 \mathrm{~g}$ intravenous methylprednisolone and after five days of $500 \mathrm{mg}$ intravenous methylprednisolone, but each time he again improved after IVIg. He reached the maximum RMI score after IVIg, but was still dependent on repeated IVIg infusions. The second patient (9) continued to deteriorate after two cycles of dexamethasone. He did not improve after either IVIg or plasma exchange but stabilised after five months of progression. Slight signs of improvement were later on noted but he was still confined to a wheelchair.
Seven patients completed treatment. Six patients had remissions sustained until now (15 to 23 months after the last cycle), and one (1) had a relapse within two months after the last dexamethasone cycle. This patient was previously known to respond beneficially to repeated IVIg infusions. The relapse after dexamethasone treatment was successfully treated with another three cycles of dexamethasone and methotrexate (MTX). With low weekly doses of MTX as a single treatment she is still improving.

All seven patients who completed treatment improved in functional health status, as measured with the RMI. Improvement of four points or more on the RMI was noted in all patients, except for patient 8 who improved two points during treatment. At follow up he had further improved to three points.

Four of the seven patients $(1,2,5,6)$ who improved during dexamethasone treatment had previously responded favourably to IVIg. These patients had not had remissions of at least six months duration before dexamethasone was started. The other three patients (4, $8,10)$ had not received any treatment before dexamethasone treatment was started. Patient 3 was the only one receiving other immunosuppressive treatment (prednisone $(20 \mathrm{mg})$, in between two dexamethasone cycles).

Five patients experienced side effects during dexamethasone treatment (table).

\section{Discussion}

In this study we found that six of 10 consecutive patients with CIDP were in remission six months after the last cycle of pulsed high dose dexamethasone treatment. Seven patients completed treatment and improved in terms of functional health status. Five patients experienced side effects varying from slight to severe.

Our results differ from those of the study in patients with ITP as not all of our patients reached remission. Moreover, treatment was less well tolerated. Treatment was discontinued in one patient because of side effects, in one patient because of further neurological deterioration, and in one patient because of severe increase of muscle weakness within one week after onset of dexamethasone treatment. This patient had a pure motor form of CIDP. Donaghy et al described four patients with purely motor CIDP who deteriorated within 
one month after starting oral prednisolone treatment. They concluded that steroids should be used with extreme caution, if at all, in this type of CIDP. ${ }^{12}$

By contrast with the patients with ITP, our patients were not refractory to other treatments. Four of seven patients who responded to dexamethasone treatment had responded to IVIg during previous relapses and three of the seven patients had not been treated before.

Although not all of these patients with CIDP reached remission after six months, the results of this study are promising when compared with other studies that analysed remission in CIDP. ${ }^{13-15} \mathrm{Up}$ to $70 \%$ of the patients with CIDP relapse when the dose of steroids is reduced and treatment schedules lasting two years have been recommended. ${ }^{16}$ Of 41 patients with CIDP who responded to IVIg, $73 \%$ needed repeated immunoglobulin infusions for at least six months, and $50 \%$ still needed treatment after two years. ${ }^{14}$

This pilot study suggests that pulsed high dose dexamethasone treatment may induce clinically significant improvement and remissions in a substantial proportion of patients with CIDP. The side effects are acceptable when remissions are sustained. This treatment regimen of steroids needs to be tested against standard treatments for CIDP.

We thank $M$ de Visser, W Weststrate, J J Korten, and J A L Vanneste for including patients in this study.

This work was presented at the Sixth Meeting of the European Neurological Society, The Hague, The Netherlands, 8-12 June 1996.

1 Dyck PJ, O'Brien PC, Oviatt KF, et al. Prednisone improves chronic inflammatory demyelinating polyradiculoneuropathy more than no treatment. Ann Neurol 1982;11:136-41.

2 Dyck PJ, Daube J, O'Brien P, et al. Plasma exchange in chronic inflammatory demyelinating polyradiculoneuropathy. New Engl f Med 1986;314:461-5.

3 van Doorn PA, Brand A, Strengers PF, Meulstee J,
Vermeulen M. High-dose intravenous immunoglobulin treatment in chronic inflammatory demyelinating polyneuropathy: a double-blind, placebo-controlled, polyneuropathy: a double-blind, placebo-c
crossover study. Neurology 1990;40:209-12.

4 Vermeulen M, van Doorn PA, Brand A, Strengers PF, Jermeulen M, van Doorn PA, Brand A, Strengers PF,
Jennekens FG, Busch HF. Intravenous immunoglobulin treatment in patients with chronic inflammatory demyelinating polyneuropathy: a double blind, placebo controlled study. F Neurol Neurosurg Psychiatry 1993;56: 36-9.

5 Dyck PJ, Litchy WJ, Kratz KM, et al. A plasma exchange versus immune globulin infusion trial in chronic inflammatory demyelinating polyradiculoneuropathy. $A n n$ Neurol 1994;36:838-45.

6 Hahn AF, Bolton CF, Vandervoort P, Feasby TE, Zochodne D. Intravenous immunoglobulin treatment (IVIg) in chronic inflammatory demyelinating polyneuropathy (CIDP): a double-blind, placebo-controlled, ropathy (CIDP): a double-blind, placebo-controllec
crossover study [abstract]. Neurology 1995;45:A416.

7 van Doorn PA, Vermeulen M, Brand A, Mulder PG, Busch HF. Intravenous immunoglobulin treatment in patients with chronic inflammatory demyelinating patients with chronic inflammatory demyelinating
polyneuropathy. Clinical and laboratory characteristics associated with improvement. Arch Neurol 1991;48: 217-20.

8 Andersen JC. Response of resistant idiopathic thrombocytopenic purpura to pulsed high-dose dexamethasone therapy. $N$ Engl $\mathcal{F}$ Med 1994;330:1560-4.

9 Vermeulen M, van der Meche FG, Speelman JD, Weber A, Busch HF. Plasma and gamma-globulin infusion in chronic inflammatory polyneuropathy. $₹$ Neurol Sci 1985 ; 70:317-26.

10 Research criteria for diagnosis of chronic inflammatory demyelinating polyneuropathy (CIDP). Report from an ad hoc subcommittee of the American Academy of Neurology AIDS Task Force. Neurology 1991;41: Neurology.

11 Collen FM, Wade DT, Robb GF, Bradshaw CM. The Rivermead mobility index: a further development of the Rivermead motor assessment. Int Disabil Stud 1991, 13:50-4.

12 Donaghy M, Mills KR, Boniface SJ, Simmons J, Wright I, Gregson N. Pure motor demyelinating neuropathy: deterioration after steroid treatment and improvement with intravenous immunoglobulin. $f$ Neurol Neurosurg Psychiatry 1994;57:778-83.

13 Dyck PJ, Lais AC, Michiya Ohta, Bastron JA, Harud Okazaki, Groover RV. Chronic inflammatory polyradiculoneuropathy. Mayo Clin Proc 1975;50:621-37.

14 van Doorn PA, van Burken M, Vermeulen M, Dippel D, van der Meche FG. Long-term iv immunoglobulin (IVIg) treatment in patients with chronic inflammatory demyelinating polyneuropathy (CIDP) [abstract]. $f$ Neurol 1996;243:S33.

15 Barohn RJ, Kissel JT, Warmolts JR, Mendell JR. Chronic inflammatory demyelinating polyradiculoneuropathy. Clinical characteristics, course, and recommendations for diagnostic criteria. Arch Neurol 1989;46:878-84.

16 Dalakas MC, Engel WK. Chronic relapsing (dysimmune) polyneuropathy: pathogenesis and treatment. Ann Neurol 1981;9:134-5. 